\title{
Despair on disparities
}

\section{Loreto Carmona, Estíbaliz Loza}

In this issue of Annals of the Rheumatic Diseases, Sokka et al (see page 1666), by analysing the data from the Quantitative Standard Monitoring of Rheumatoid Arthritis (QUEST-RA) cohort, with over 6000 patients from 25 countries, warn us of possible disparities in the health of patients with rheumatoid arthritis. ${ }^{1}$ This international team of researchers found a clear association between gross domestic product and the average status of the patients. We believe it is imperative to review some concepts that may help to understand the implications of these results.

Health inequalities, disparities, or variability in health, may be defined as differences in health status or in the distribution of health determinants between different population groups (ie, differences in mobility between older individuals and younger ones, or differences in death rates between social classes). It is important to distinguish them from inequities. Inequity means that the difference is unfair, a matter of injustice. Some health inequalities are attributable to biological variations or even to the free choice of individuals, while others may be attributable to external sources, mainly outside the control of those concerned. In the first case it may be impossible, or ethically or ideologically unacceptable to modify the health determinants and so the health inequalities are inevitable. In the second, the uneven distribution may be unnecessary and avoidable as well as unjust and unfair, so that the resulting health inequalities also lead to inequity in health. ${ }^{2}{ }^{3}$

Reports on health inequalities exist between countries, within countries, between regions, health systems (including hospitals and doctors), individuals, etc, for which different explanatory reasons have been proposed (socioeconomical, political, cultural, etc.). Differences in death rate are some of the most relevant health inequalities reported and, with regard to socioeconomic factors, some of

Research Unit, Fundación Española de Reumatología, Madrid, Spain

Correspondence to: Dr Loreto Carmona, Unidad de Investigación, Fundación Española de Reumatología, Calle Marqués del Duero, 5, 1, 28001 Madrid, Spain; loreto.carmona@ser.es the most important associated factors. ${ }^{4}$ According to the World Health Organization (WHO), life expectancy in high-income countries is 79.4 years whereas it barely reaches 49.2 years in low-income African countries. ${ }^{2}$ In poor countries, more than $80 \%$ of deaths are related to infections, an avoidable cause that is related to only $4 \%$ of the deaths in rich countries. In addition, 7 out of 10 child deaths occur in Africa and South East Asia. These data clearly highlight that health inequalities all around the world are largely caused by economic differences. ${ }^{5}$ Political conflicts, weak health systems, barriers to access, inadequate human resources, poor infrastructures, as well as cultural beliefs and learnt behaviours continue to be major obstacles in low-income countries. ${ }^{6}$

Although probably not to the extent of what has been observed in poor countries, we may also find health inequities in developed countries. In a recent publication, 22 European countries exhibited differences in death rate from selected causes, the authors suggesting that some variations could be attributable to differences in smoking, alcohol intake and access to health care. ${ }^{7}$ Also, geographic variability in the same country has been recognised as a major factor in prescribing for chronic diseases in older people, ${ }^{8}$ or in attitudes towards elective caesarean section on maternal request, ${ }^{9}$ etc.

Inequalities are unfair. Distinguishing between health inequalities and health inequities can be contentious. Our view is that inequalities become "unfair" when poor health is itself the consequence of an unjust distribution of the underlying social determinants of health (for example, unequal opportunities in education or employment). Sometimes it is unknown to what extent health variability or inequalities are modifiable or due to biology. But often, investigations into the health of groups and the determinants of health inequities that lie outside the control of the individual have received a much smaller share of research resources. Even with these limitations, unfortunately, several health inequities are present in the world. Gender inequities, for instance, have extensively been reported..$^{10}$ It is estimated that blindness and severe visual impairment from cataracts could be reduced by around $11 \%$ in the low-income and middle-income countries if women were to receive cataract surgery at the same rate as men. ${ }^{11}$ In Chile, in the private health sector women pay higher insurance premiums than men, and among children, boys aged 2 years or less have 2.5 times more preventive consultations than girls. ${ }^{12}$

There are plenty of examples of variability in rheumatology, such as those in lupus, ${ }^{13}$ with poorer patients having poorer outcomes, ${ }^{14}$ in scleroderma, ${ }^{15}$ juvenile idiopathic arthritis, ${ }^{16}$ or osteoarthritis. ${ }^{17}$ In rheumatoid arthritis (RA) there are examples of variability in drug utilisation, ${ }^{18}$ in access to specialist services, ${ }^{19} 20$ and in outpatient consultation, hospitalisation, or surgical rates, including joint replacement procedures, with poorer patients faring lower in all rates. ${ }^{21-26}$ Interestingly, socioeconomic features are documented as a main factor in health inequalities in patients with musculoskeletal disorders in health systems with universal insurance coverage $e^{26}$ and in those without it. ${ }^{27}$ This is what Sokka et al's article is mainly related to: socioeconomic or related factors underlying differences in health status. Furthermore, some authors preclude collecting measures of deprivation for patients enrolled in clinical trials, longitudinal observational studies and in the clinical setting, as they may be sound confounders. ${ }^{28}$ Besides socioeconomic factors, other sources of health disparities in rheumatology are at play: patients' preferences, ${ }^{29} 30$ age and ethnicity, ${ }^{31}$ factors related to the doctor or the centre, ${ }^{32}{ }^{33}$ and other cultural or economic factors that may interfere with, for instance, the return to work in patients with the same disease severity. ${ }^{34}$

How could we identify opportunities for reducing inequalities in health? First of all, measuring disparities should advise us on where to start with. For this purpose, there are many efforts now within European rheumatology, such as the European Musculoskeletal Conditions Surveillance and Information Network (eumusc.net) joint European League Against Rheumatism (EULAR)/European Union (EU) sponsored dynamic database covering the best available data on the occurrence, impact and availability of health care resources relevant to musculoskeletal disorders in the different member European countries (http://www.eular. org/), and at a larger level, such as the International World Bank initiative updating data used in the Global Burden of Disease project. ${ }^{35}$ Secondly, there is a need to improve performance by reviewing 
national guidelines and differences between them, and by looking at barriers for implementing them, in a collaborative effort beyond countries. Thirdly, there is a need to acknowledge that inequalities affect everyone. Conditions that lead to marked health disparities are detrimental to all members of society (ie, the spread of infectious diseases, the consequences of alcohol and drug misuse, or the occurrence of violence and crime). These arguments, to measure, to improve, to become part of a larger self, should all be embedded in our education as doctors and as citizens.

In all, disparities in health are avoidable as they may stem from identifiable policy options exercised by governments, such as tax policies, business and labour regulation, welfare benefits and health care funding. Health inequalities are, therefore, amenable to policy interventions. And they are not only avoidable; it pays to reduce them. Interventions to decrease health inequalities are cost effective. ${ }^{36}{ }^{37}$ The case can be made to give priority to such programs on efficiency grounds.

In summary, differences in health status that may not be biologically determined occur in rheumatology. These differences are avoidable, although the mechanisms giving rise to inequalities are still imperfectly understood, and evidence remains to be gathered on the effectiveness of interventions to reduce such inequalities. Fairness should be the principal argument to reduce disparities in health. We, as the European rheumatological community, have to strive actively for the reduction of all avoidable inequities. We have the data, let's not ignore them.

Competing interests: None declared.

Provenance and peer review: Commissioned; externally peer reviewed.

Accepted 31 August 2009

Ann Rheum Dis 2009;68:1657-1658.

doi:10.1136/ard.2009.115519

\section{REFERENCES}

1. T Sokka, H Kautiainen, $\mathrm{T}$ Pincus, et al. Disparities in rheumatoid arthritis disease activity according to gross domestic product in 25 countries in the QUESTRA database. Ann Rheum Dis 2009;68:1666-72.

2. World Health Organization. Health Impact Assessment (HIA). Glossary of terms used 2009 http://www.who.int/hia/about/glos/en/index1.html (accessed 15 July 2009).

3. Meghani SH, Gallagher RM. Disparity vs inequity toward reconceptualization of pain treatment disparities. Pain Med 2008 ;9:613-23.

4. Cosgrove S. Poverty, health and participation. Ir Med J 2007;100(Suppl):73-5.

5. Mathers C, Fat DM, Boerma JT, et al. Part 1. Introduction. In: The global burden of disease: 2004 update. Geneva, Switzerland: World Health Organization, 2008: 1-6.

6. Vitoria M, Granich R, Gilks CF, et al. The global fight against HIV/AIDS, tuberculosis, and malaria: current status and future perspectives. Am J Clin Pathol 2009:131:844-8.

7. Mackenbach JP, Stirbu I, Roskam AJ, et al. Socioeconomic inequalities in health in 22 European countries. N Engl J Med 2008;358:2468-81.

8. Naughton C, Bennett K, Feely J. Regional variation in prescribing for chronic conditions among an elderly population using a pharmacy claims database. Ir J Med Sci 2006;175:32-9.

9. Bergholt T, Ostberg B, Legarth J, et al. Danish obstetricians' personal preference and general attitude to elective cesarean section on maternal request: a nation-wide postal survey. Acta Obstet Gynecol Scand 2004;83:262-6.

10. Gita S, Piroska Ö, Asha G, et al. Unequal, unfair, ineffective and inefficient gender inequity in health why it exists and how we can change it. Final report to the WHO Commission on Social Determinants of Health. http://www.who.int/social determinants/ resources/csdh_media/wgekn_final_report_07.pdf (accessed 15 July 2009).

11. Lewallen S, Mousa A, Bassett $K$, et al. Cataract surgical coverage remains lower in women. Br J Ophthalmol 2009:93:295-8.

12. Vega J, Bedregal $P$, Jadue $L$, et al. Gender inequity in the access to health care in Chile. Rev Med Chil 2003;131:669-78.

13. Fernandez M, Alarcon GS, Calvo-Alen J, et al. A multiethnic, multicenter cohort of patients with systemic lupus erythematosus (SLE) as a model for the study of ethnic disparities in SLE. Arthritis Rheum 2007; 57:576-84.

14. Peschken CA, Katz SJ, Silverman E, et al. The 1000 Canadian faces of lupus: determinants of disease outcome in a large multiethnic cohort. J Rheumatol 2009;36:1200-8.

15. Walker UA, Tyndall A, Czirjak L, et al. Geographical variation of disease manifestations in systemic sclerosis: a report from the EULAR Scleroderma Trials and Research (EUSTAR) group database. Ann Rheum Dis 2009;68:856-62.

16. Seid M, Opipari L, Huang B, et al. Disease control and health-related quality of life in juvenile idiopathic arthritis. Arthritis Rheum 2009;61:393-9.

17. Wilson MG, May DS, Kelly JJ. Racial differences in the use of total knee arthroplasty for osteoarthritis among older Americans. Ethn Dis 1994;4:57-67.

18. Gonzalez-Alvaro I, Hernandez-Garcia C, Villaverde Garcia V, et al. Variations in the drug treatment of rheumatoid arthritis in Spain [in Spanish]. Med Clin (Barc) 2002;118:771-6.

19. Zink A, Listing J, Ziemer S, et al. Practice variation in the treatment of rheumatoid arthritis among German rheumatologists. J Rheumatol 2001;28:2201-8.

20. Shipton D, Glazier RH, Guan J, et al. Effects of use of specialty services on disease-modifying antirheumatic drug use in the treatment of rheumatoid arthritis in an insured elderly population. Med Care 2004;42:907-13.

21. Katz S, Vignos PJ Jr, Moskowitz RW, et al. Comprehensive outpatient care in rheumatoid arthritis. A controlled study. JAMA 1968;206:1249-54.

22. Clarke AE, Esdaile JM, Hawkins D. Inpatient rheumatic disease units: are they worth it? Arthritis Rheum 1993;36:1337-40.

23. Vitale MG, Krant JJ, Gelijns AC, et al. Geographic variations in the rates of operative procedures involving the shoulder, including total shoulder replacement, humeral head replacement, and rotato cuff repair. J Bone Joint Surg Am 1999;81:763-72.

24. Coyte PC, Hawker G, Wright JG. Variations in knee replacement utilization rates and the supply of health professionals in Ontario, Canada. J Rheumatol 1996;23:1214-20.

25. Loza $\mathbf{E}$, Abasolo L, Clemente D, et al. Variability in the use of orthopedic surgery in patients with rheumatoid arthritis in Spain. J Rheumatol 2007;34:1485-90.

26. Jacobi CE, Mol GD, Boshuizen HC, et al. Impact of socioeconomic status on the course of rheumatoid arthritis and on related use of health care services. Arthritis Rheum 2003;49:567-73.

27. Gittelsohn AM, Halpern J, Sanchez RL. Income, race, and surgery in Maryland. Am J Public Health 1991;81:1435-41.

28. Harrison MJ, Tricker KJ, Davies L, et al. The relationship between social deprivation, disease outcome measures, and response to treatment in patients with stable, long-standing rheumatoid arthritis. J Rheumatol 2005;32:2330-6.

29. Lurie JD, Berven SH, Gibson-Chambers J, et al. Patient preferences and expectations for care: determinants in patients with lumbar intervertebral disc herniation. Spine (Phila Pa 1976) 2008;33:2663-8.

30. Lofvendahl S, Eckerlund I, Hansagi $\mathrm{H}$, et al. Waiting for orthopaedic surgery: factors associated with waiting times and patients' opinion. Int J Oual Health Care 2005;17:133-40.

31. Dunlop DD, Manheim LM, Song J, et al. Age and racial/ethnic disparities in arthritis-related hip and knee surgeries. Med Care 2008;46:200-8.

32. Wright JG, Hawker GA, Bombardier C, et al. Physician enthusiasm as an explanation for area variation in the utilization of knee replacement surgery. Med Care 1999;37:946-56.

33. Katz JN, Barrett J, Mahomed NN, et al. Association between hospital and surgeon procedure volume and the outcomes of total knee replacement. J Bone Joint Surg Am 2004;86A:1909-16.

34. Chung CP, Sokka T, Arbogast PG, et al. Work disability in early rheumatoid arthritis: higher rates but better clinical status in Finland compared with the US. Ann Rheum Dis 2006;65:1653-7.

35. World Health Organization. Global burden of disease. http://www.who.int/topics/ global_burden_of_disease/en/ laccessed 31 July 2009).

36. Stebbins MR, Kaufman DJ, Lipton HL. The PRICE clinic for low-income elderly: a managed care model for implementing pharmacist-directed services. J Manag Care Pharm 2005;11:333-41.

37. Antunes JL, Waldman EA, Borrell C, et al. Effectiveness of influenza vaccination and its impact on health inequalities. Int $\mathrm{J}$ Epidemiol 2007;36:1319-26. 